\title{
Dentistry in South Africa and the need for management and leadership training
}

SADJ October 2021, Vol. 76 No.9 p532 - p536

MO Tukuru1, L Snyman², TC Postma ${ }^{3}$, SE van der Berg-Cloete ${ }^{4}$

\section{ABSTRACT}

\section{Introduction}

Dental professionals face many challenges due to a rapidly changing environment, and are acknowledging the need for essential leadership skills to perform optimally. We assessed key stakeholders' views about the need for management and leadership training in dentistry in South Africa .

\section{Aims and objectives}

The aim of this study, was to assess the need for leadership and management training in Dentistry in South Africa from an industry perspective.

\section{Design}

A qualitative study.

\section{Methods}

Purposive sampling of 14 Senior Managers in the dental environment and 11 recently qualified dentists in South Africa. We conducted one-on-one and telephonic interviews guided by a semi-structured questionnaire with open-ended questions. Interviews were recorded, transcribed and data was thematically analysed.

\section{Author affiliations:}

1. Michelle Olubunmi Tukuru: BDS, Primary Fellowship Exam of Faculty of Dental Surgery of West African College of Surgeons, PG Dip Dent (Practice Management) MSc Dent (Gen). Department of Dental Management Sciences, School of Dentistry, University of Pretoria, Pretoria, SA

2. Lorraine Snyman: BChD, PG Dip Dent (Clinical Dentistry), PG Dip Dent (Practice Management), PGCHE, MBL, Senior Lecturer: Department of Dental Management Sciences, School of Dentistry, University of Pretoria, Pretoria, SA

3. Thomas Corne Postma: BChD, MChD(Com Dent), DHSM, $P h D$, Associate Professor: Department of Dental Management Sciences, School of Dentistry, University of Pretoria, Pretoria, SA

4. Sophy Evelyn van der Berg-Cloete: BChD, PG Dip Dent (Community Dentistry), MBA, DHSM, PhD, Adjunct-Professor: Department of Dental Management Sciences, School of Dentistry, University of Pretoria, Pretoria, SA

Corresponding author:

Sophy Evelyn van der Berg-Cloete

Department of Dental Management Sciences, School of Dentistry, Faculty of Health Sciences, Bophelo Road, Pretoria, 0001, South Africa

Tel: $+27(0) 123192935$

Fax: +27 (0) 866093888

Email: Sophy.vanderBerg-Cloete@up.ac.za

\section{Author contributions:}

1. Michelle Olubunmi Tukuru: $50 \%$ (1st author and principal researcher)

2. Lorraine Snyman: $15 \%$ (article contribution)

3. Thomas Corne Postma: $15 \%$ (co-supervisor and article contribution)

4. Sophy Evelyn van der Berg-Cloete: $20 \%$ (supervisor of research \&article contribution)

\section{Results}

Participants expressed concerns about dentistry in South Africa. All participants mentioned financial constraints, including the high cost of setting up a practice, high cost of imported consumables and dwindling support from medical schemes. Participants stated that strong leadership and managerial skills were important for dealing with these challenges.

\section{Conclusion}

Inculcating these skills will make a remarkable difference in enhancing services and providing purposive direction within the profession.

\section{Keywords}

Dentistry, leadership; management; leadership training and development

\section{INTRODUCTION}

Dental professionals are gradually acknowledging that they need to obtain important leadership skills to achieve professional competency. The extent and development of these leadership skills in the tertiary education system have not been well defined, ${ }^{1}$ and require urgent attention because the dental profession is rapidly changing. ${ }^{2}$ A significant decline in incidence of dental caries and shifting disease pattern, ${ }^{3}$ in the wake of increasing demands from patients' high expectations, challenges with medical aid coverage and occupational safety has altered the face of the dental profession. ${ }^{4}$ In addition, also consequent to the link between oral infections and systemic diseases, developing health reforms compete with the traditional model and scope of practicing. ${ }^{5}$ South African dentists urgently need to acquire leadership and management skills to enhance their optimal performance in complex environments. ${ }^{6}$

Dental education and training encompasses a wide range of skills, but leadership skills are rarely purposefully cultivated. In South Africa, dental students' training is largely centred around clinical practice, despite evidence showing that dental students believe that leadership skills are imperative in their education. ${ }^{7}$ Studies also show that dentists in private practice support the development of leadership skills during tertiary training, since these skills are lacking in practice. ${ }^{8}$

South Africa is facing many healthcare challenges, which may be mitigated through the development of leadership skills, encouraging health professionals to work together for the benefit of the South Africa population. ${ }^{9}$ Irrespective of legislative measures granting good policies, a shortage of leadership and management skills complicated by insufficient 
attention to health inequalities, have a considerable impact on how the healthcare system is implemented. ${ }^{10}$ A recent study in South Africa found that dental students recognised the need for training in non-clinical, as well as clinical skills. ${ }^{11}$ The majority of them were hoping to engage themselves with the private sector in the future, however, these hopes may be modified under the transformation of dental education within the last two decades, including ongoing social redress being directed at racial profiling in the universities. ${ }^{12}$ The students expressed a need for leadership and management training in dental schools in South Africa. To date, there has been no consensus on this topic from the other key stakeholders in the dental fraternity. We add to the perspectives of dental students, by assessing the views of dental senior managers and practicing South African dentists. In this study we assessed key stakeholders' views about dentistry in South Africa, and if they believed there was a need for management and leadership training in dentistry. Our findings will shed light on the professional environment of dentistry in South Africa and prompt educators to make evidence-based decisions on the urgency of including or developing leadership and management in dentistry curricula.

\section{METHODS AND MATERIALS}

Ethical approval (352/2016) was granted from the University $X$ Ethics Committee.

\subsection{Study design}

For this qualitative study, we purposively sampled senior managers and practising dentists. Our sample included 14 dentists in Senior Managers, and 11 recently qualified dentists. The Senior managers included dentists from reputable public and private oral health organisations, including the South African Dental Association (SADA), Dental Professionals association (DPA), group practices (Intercare and Medicare), South African Military Health Services (SAMHS), Public Health Services (National Department of Health and the regional Tshwane district) and five private dentists. Dentists were selected due to their role, experience and ability to provide valuable information on management and leadership pertaining to oral health in South Africa.

The Young dentists included dentists from the public $(n=5)$ and private $(n=6)$ sectors, who qualified between 2002 and 2015, and were younger than 35 years old. Dentists represented four of the nine provinces in South Africa, namely Gauteng, Kwa-Zulu Natal, Mpumalanga and Western Cape.

All the participants were invited telephonically or via email. The emails sent contained the title and objectives of the research study, the nature of the involvement of the participants and what was expected of them. Participants who indicated interest in being part of the study, signed an informed consent.

\subsection{Data collection}

Data were collected during semi-structured interviews, conducted either in person or telephonically..$^{13}$ The study was approved by the University X Ethics Committee (352/2016). The Senior Managers and Young Dentists were asked a set of pre-determined open-ended questions: "What are your views about dentistry in South Africa?", "Do you think there is a need for leadership and management training in dentistry in South Africa?" and "Do you know of any initiatives focusing on leadership and management training in dentistry in South
Africa?" We also asked the Young Dentists whether they felt that their dental training had satisfactorily equipped them with appropriate non-clinical skills to successfully launch a dental practice.

\subsection{Data analysis}

We coded each participant to ensure anonymity i.e. SM01SM14 (Senior Managers) and YD01-YD11 (Young Dentists). Interviews were audio-recorded, and responses were transcribed verbatim, and thematically analysed. ${ }^{14}$

\section{RESULTS}

3.1 The state of dentistry in South Africa

From the question assessing the perceptions of dentists on the state of dentistry in South Africa, we identified three themes, including (1) Expensive and unaffordable dental services; (2) Reduced pay-outs from third party funders; (3) Marginalisation of dentistry from other medical professions within the health sector.

\section{Expensive and unaffordable dental services}

All the participants agreed that the dental profession in South Africa is undergoing major challenges.

"The dynamics and diversity of South Africa as a country makes it even more challenging" (SM13).

Most $(n=10)$ of the SMs stated that dentistry is currently under strain and pressure from the external environment such as the economy. Dentists also felt that dentistry serves the overall good of the public despite being expensive. Dentistry is no longer viewed as a priority in general healthcare especially by third party funders in South Africa.

"Dentistry is expensive. People cannot afford services. Even those on medical aid" (SMO5).

One participant stated that South Africa had an adequate dental system but that proper implementation was a concern,

"This starts with undergraduate training where teaching should be centred on the primary healthcare approach i.e. prevention and promotion, early diagnosis/detection, curative, and rehabilitation, instead of largely on curative, as was mainly the approach currently. This primary healthcare approach will benefit oral health in general and the society as a whole" (SM14).

Most $(n=8)$ Young Dentists felt that dentistry in South Africa was highly constrained and challenging. These challenges included dentistry being demanding, and medical counter parts not viewing oral health as a priority, and therefore delaying referrals. Dentists also mentioned economic fluctuations as a challenge, including often-volatile exchange rates affecting the cost of imported dental consumables.

"Another pressure also is our exchange rate which is been very volatile. Everything is imported and subject to the dollar, pound or euro" (YDO7).

\section{Reduced pay-outs from third party funders}

Almost half $(n=6)$ of SMs agreed that the dental profession was seriously threatened by reduced pay-outs from medical 
schemes. Dental services have become an out of pocket expenditure for most clients.

"I love clinical practice, but the main frustration is with the reduction in medical aid pay-outs leading to poor treatment planning and overcompensating with a heavy workload" (SM06).

Two Young Dentists also suggested that there was a need to acquire leadership and management skills to effect relevant changes regarding medical schemes.

\section{Marginalization of dentistry from other medical professions within the health sector}

Three Senior Managers noted that the dental profession is being marginalised by their medical health counterparts. Participants suggested that dentistry should be prioritised in the health agenda of South Africa. The lack of advocacy for dentistry in South Africa was attributed to a lack of management and leadership skills in the profession.

"We need leaders in dentistry that will collaborate dentistry with private stakeholders and boost the economy. We need leaders and managers in dentistry that will now effect a change with collaboration because we are isolated" (SMO3).

Three Young Dentists also expressed concerns that oral health might not be considered important for general health and wellbeing and mentioned that more attention should be placed on oral health resources. Participants mentioned that this is particularly relevant in the public sector, where awareness of dentistry should be emphasised. One participant highlighted funding conflicts between dentistry and medicine and pointed out the disconnect between dentistry in the private and public sectors. One Young Dentist who previously worked for the public sector, stated that there were too few dentists in the public sector, posing a challenge and alluding to the huge demand for services.

3.2 The need for leadership and management training in South Africa

Participants acknowledged that management and leadership were often used interchangeably. Senior Managers confirmed the need for both management and leadership amongst dentists in South Africa.

"Definitely a need for both. Leadership: to get things done through people working together to share and implement your vision. On the operational side of things as well, managers are needed" (SMO7).

Senior Managers agreed that there is an incorrect perception that leadership skills develop with clinical experience and age. All $(n=5)$ the private sector Senior Managers, unanimously supported that management and leadership skills were a critical requirement for dentists. This is because, most qualified dentists in South Africa end up in the private sector during the course of their career. Some dentists will eventually manage their own practices, and one Senior Manager mentioned that these dentists are business owners and should have a general knowledge of human resources and development, finances, fixed and variable costs, and how these affect the business. As leaders, dentists should be able to forecast, look into the future and have a vision of how they are going to take the practice forward. This speaks to entrepreneurial thinking and vision.

Most of the Young Dentists $(n=8)$ agreed that dentists need both management and leadership skills. One Young Dentists mentioned that clinical skills were the primary focus of dental training. Most dentists qualify with adequate clinical competency, proficiency and knowledge, but without the non-clinical skills needed to work as part of a team rather than running a one-person show.

Five Senior Managers and two Young Dentists felt that there was a stronger need for management training. According to one Senior Manager, many South African dentists leave the management of their practices up to their non-clinical staff. Many dentists in private practice lack knowledge about staff, stock control, equipment, supply chain and service providers. Only three Senior Managers and one Young Dentist favoured leadership training. Only one Young Dentist, who was foreign trained, felt that he was adequately trained in non-clinical skills. The rest of the Young Dentists felt they lacked the necessary non-clinical skills. Only eight Senior Managers and five Young Dentists knew of self-sought management courses offered by professional bodies. Participants felt that the general management courses organised by the academic institutions for dental students were rather broad, and not structured to suit the dental curriculum. Only three Senior Managers and three Young Dentists identified a few leadership development initiatives. These participants wished to see leadership initiatives relevant to the dental profession.

\section{DISCUSSION}

In this study, we assessed the perceptions of practising dentists regarding how they perceived dentistry in South Africa, and if they felt there was a need for management and leadership training in dentistry in South Africa. As a whole, participants were pessimistic about dentistry in South Africa. Participants were frustrated at the high input costs, inadequate funding due to increasing pressure from third party funders and marginalization of dentistry.

In South Africa, medical aid coverage dropped from 18\% in 1996 to $11 \%$ in 2003 , implying that an increasing number of patients are attending the already overburdened public healthcare facilities. ${ }^{15}$ More than $80 \%$ of the private practices in South Africa depend on medical aid, providing expensive private dental care to those who are able to afford monthly medical aid payments. ${ }^{16}$ The significant challenge in dentistry in South Africa, is connected to the considerable social and economic inequalities of South Africans stemming from a history of apartheid. ${ }^{17}$

Socioeconomic disparities mean that many people are unable to afford dental treatment, ${ }^{18}$ due to the high rate of unemployment amongst South Africans. ${ }^{19}$ Dentists are thus put under pressure by dwindling numbers of patients, and high costs of setting up surgeries and having to import expensive consumables.

The situation in dentistry has been made more difficult by the increasing complexity of health in South Africa, which disregards dentistry as a health priority. ${ }^{20-21}$ Most dental services are rendered to relieve pain and sepsis, regardless of the need for advanced treatment. ${ }^{21}$ In South Africa, there 
are good health policies, but the lack of good leadership and management has hindered the full implementation of many policies. ${ }^{10}$ South Africa needs leaders and managers in strategic positions who can motivate for transformation and implement policies to improve oral healthcare service delivery in South Africa.

In this study, all participants agreed that dentists need management and leadership training. Participants recognised that not having these skills resulted in real leadership and management challenges. Other studies recognise the importance of leadership skills for dentists since they inevitably end up leading their own teams. ${ }^{22-23}$ These skills are needed to encourage change and innovation while at the same time equip professionals to master challenges. ${ }^{22}$ Most of the Senior Managers and Young Dentists confirmed that they did not have the sufficient training in non-clinical skills to adequately prepare them for dental practice. The Senior Managers confirmed that they did not receive any management training during their undergraduate dental training. This was contrary to the Young Dentists, who ran modules in Dental Practice Management as part of their undergraduate curriculum, but still felt inadequately prepared for leadership roles in the dental profession.

Dental professionals should be trained in leadership knowledge and skills. ${ }^{24}$ Yet, dental schools have not adequately incorporated the necessary leadership skills to prepare dental professionals for leadership roles. ${ }^{25-27}$ Dental students are generally not trained to become proficient in non-clinical skills, such as communication and teamwork. Imparting management and leadership training early at undergraduate level could potentially have remarkable benefits. Apart from a better understanding of how to lead a dental team, this training could assist educators to quickly recognise future leaders. Students could aspire to and grow into awareness of their innate leadership abilities. ${ }^{25}$ Participants further revealed that there were few initiatives developing leadership and management skills in dentistry in South Africa.

Dentists in South Africa, are experiencing significant challenges, both in the public and private sectors. Dentists require leadership and management training to deal with these challenges. Dental institutions need to review their curricula to incorporate management and leadership training. This study contributes to the scarce literature around leadership and management skills in dentistry.

\section{LIMITATIONS OF THE STUDY}

The sample size was relatively small, which may affect the generalisability of the study. It could however be argued that the key stakeholders who were consulted in this study were fairly representative of the incumbent organisational leadership in dentistry in South Africa. Young Dentists also originated from multiple training institutions to give a perspective of their recent education.

\section{CONCLUSION}

Key stakeholders' opinions advocated that dentists in South Africa are very pessimistic about the changing environment. There are clear indications that they are inadequately equipped to deal with funding frustrations and the alleged marginalization of dentistry. Dentistry is perceived to be less important in the South African healthcare system.
Leadership and management skills are required to ensure the sustainability of dentistry as a profession, and contribute appropriately to the healthcare system.

\section{Conflicts of Interest}

The authors have no conflicts of interest to disclose.

\section{References}

1. Garman AN, Butler P, Brinkmeyer I. Leadership. J Healthc Manag 2006; 51(6): 360-4.

2. Townsend $G$, Thomas R, Skinner V, et al. Leadership, governance and management in dental education-new societal challenges. Eur J Dent Educ 2008; 12(S1): S131-48.

3. Marthaler TM. Changes in dental caries 1953-2003. Caries research. 2004; 38: 173-81.

4. Brown LJ. Introduction and guide to the special issue on economic and workforce issues facing dentistry and dental education in the twenty-first century. J Dent Educ 2012; 76(8): 965-72.

5. Glick M. Expanding the dentists' role in health care delivery. JADA. 2009; 140(11): 1340-2.

6. Snyman L, van der Berg-Cloete SQ, White JG. The perceptions of South African dentists on strategic management to ensure a viable dental practice. S Afr Dent J 2016; 71(1): 12-8.

7. Frymier AB, Shulman GM. "What's in it for me?" Increasing content relevance to enhance students' motivation. Commun Educ 1995; 44(1): 40-50.

8. Patel R, Eaton KA, Garcia A, Rincon V, Adams L, Brook J. Factors influencing dental practitioner performance: A summary of recent literature review. Oral Health Dent Manag 2011; 10(3): 119-30.

9. Ireri S, Walshe $\mathrm{K}$, Benson L, Mwanthi MA. A qualitative and quantitative study of medical leadership and management: experiences, competencies, and development needs of doctor managers in the United Kingdom. J Manag Marketing Healthc 2011; 4(1): 16-29.

10. Dhai $A$, Veriava $Y$. Health inequity in SA-a by product of injustice. Aust N Z J Public Health 2012; 36(6): 520.

11. Van der Berg-Cloete SE, Snyman L, Postma TC, White JG. Dental students' perceptions of practice management and their career aspirations. Afr $\mathrm{J}$ Health Prof Educ 2015; 7(2): 194-8.

12. Lalloo R, Ayo-Yusuf OA, Yengopal V. Early-phase dental students' motivations and expectations concerning the study and profession of dentistry. S Afr Dent J 2008; 63(4): 216-20.

13. Gill P, Stewart K, Treasure E, Chadwick B. Methods of data collection in qualitative research: interviews and focus groups. Br Dent J 2008; 204(6): 291-5.

14. Braun V, Clarke V. Using thematic analysis in psychology. Qual Res Psychol 2006; 3(2): 77-101.

15. Shisana O, Rehle T, Louw J, Zungu-Dirwayi N, Dana $\mathrm{P}$, Rispel L. Public perceptions on national health insurance: moving towards universal health coverage in SA. S Afr Med J 2006; 96(9): 814-8.

16. Lamiraud K, Booysen F, Scheil『Adlung $X$. The impact of social health protection on access to health care, health expenditure and impoverishment: A case study of SA 2005.

17. Coovadia H, Jewkes R, Barron P, Sanders D, Mclntyre $D$. The health and health system of SA: historical roots of current public health challenges. Lancet 2009; 374(9692): 817-34. 
18. Ayo-Yusuf IJ, Ayo-Yusuf OA, Olutola BG. Health insurance, socio-economic position and racial disparities in preventive dental visits in SA. Int J Environ Res Public Health 2013; 10(1): 178-91.

19. Leibrandt M, Woolard I, McEwen H, Koep C. Employment and Inequality Outcomes in South Africa. University of Cape Town: Southern Africa Labour and Development Research Unit 2010: 45-6.

20. Kahn K. Population health in SA: dynamics over the past 2 decades. J Public Health Policy 2011; 32(1): S30-6.

21. Mostert VC, Postma TC. The capacity of the Oral Health Centre, University of Pretoria, to complete root canal treatments. S Afr Dent J 2016; 71(8): 356-60.

22. Holt VP. The need for leadership and vision in dentistry. A personal view. Prim Dent Care 2008; 15(3): 113-9.

23. Hebbal M, Ankola A, Murugaboopathy V, Patel S, Patel N, Parkar N. Do Dentists Require Leadership Qualities?. Can Med Educ J 2012; 3(1): e80-1.

24. Miller DL, Umble KE, Frederick SL, Dinkin DR. Linking learning methods to outcomes in public health leadership development. Leadersh Health Serv 2007; 20(2): 97123.

25. Morison S, McMullan C. Preparing for the future: challenges and opportunities for management and leadership skills. Br Dent J 2013; 214(1): E2.
26. Seaman C. Leadership in dentistry: an empirical phenomenological study of practicing general dentists in South Idaho. PhD Thesis. University of Phoenix 2008.

27. Willeford R. 10 steps to a financially healthy practice, Part 1. Dent Econ 2006; 96(6): 22-6.

\section{Do the CPD questionnaire on page 571}

The Continuous Professional Development (CPD) section provides for twenty general questions and five ethics questions. The section provides members with a valuable source of CPD points whilst also achieving the objective of CPD, to assure continuing education. The importance of continuing professional development should not be underestimated, it is a career-long obligation for practicing professionals.

\section{Online CPD in 6 Easy Steps}

\section{Go to the SADA website www.sada.co.za.}

Log into the 'member only' section with your unique SADA username and password.

Select the CPD navigation tab.

Select the questionnaire that you wish to complete.

Enter your multiple choice answers. Please note that you have two attempts to obtain at least $70 \%$

View and print your CPD certificate. 